\title{
Bixa orellana L. (achiote) tissue culture: a review
}

\author{
Jaime A. Teixeira da Silva ${ }^{1,2} \cdot$ Songjun Zeng ${ }^{3}$. Gregorio Godoy-Hernández ${ }^{4} \cdot$ Renata Rivera-Madrid $^{4}$. \\ Judit Dobránszki ${ }^{2}$
}

Received: 21 June 2018 / Accepted: 1 March 2019 / Published online: 1 April 2019 / Editor: Masaru Nakano

(C) The Author(s) 2019

\begin{abstract}
Bixa orellana L. (achiote) is a commercially important plant grown for its natural dye annatto, which is derived from the arils of seeds. Annatto, which contains the antioxidant bixin, is used in food, cosmetic, and textile industries as a natural colorant. Even though $B$. orellana can be propagated by seed, established tissue culture and in vitro propagation protocols exist for this plant. Organogeneses, both axillary and adventitious, as well as somatic embryogenesis, have been successfully induced from different explant sources, including cotyledons, hypocotyls, roots, stems, and leaves, and effective acclimatization protocols exist for regenerated plantlets. This present mini-review highlights the achievements in the tissue culture of achiote. In addition to using in vitro techniques for the clonal propagation of elite plants, knowledge from these protocols could be used to establish mass production systems, such as bioreactors, to facilitate year-round bixin harvest.
\end{abstract}

Keywords Biotechnology $\cdot$ Bixaceae $\cdot$ Bixin $\cdot$ Medicinal plants $\cdot$ Norbixin

\section{Introduction}

The genus Bixa (Bixaceae) contains five accepted species (Baer 1976; The Plant List 2019), of which the most popular and commercially exploited is Bixa orellana L. (achiote), an evergreen shrub native to tropical Central and South America and cultivated for its seeds there, and in other tropical countries around the world (Leal and Michelangeli De Clavijo 2010). To avoid confusion that could arise because the English common name for $B$. orellana - annatto-is shared with the name of the dye derived from the plant, the Spanish designation 'achiote' has been employed throughout the present review to denote the plant.

The major constituent ( 70 to $80 \% \mathrm{w} / \mathrm{w}$ ) of dried seed arils that contributes to annatto, a coloring agent used in food, cosmetic, and textile dyes, is the carotenoid bixin (BXN; $9^{\prime} \mathrm{Z}-6,6^{\prime}-$

Jaime A. Teixeira da Silva

jaimetex@yahoo.com

Songjun Zeng

zengsongjun@scbg.ac.cn

$\triangle$ Gregorio Godoy-Hernández

ggodoy@cicy.mx

$\triangle$ Renata Rivera-Madrid

renata@cicy.mx

Judit Dobránszki

dobranszki@freemail.hu diapocarotene-6,6'-dioate), whereas the water-soluble norbixin (NBX) is found in smaller amounts (Saha and Sinha 2012; Tupuna et al. 2018). Natural cross-pollination and resulting heterozygosity make it impossible to propagate elite achiote clones or varieties by seeds, because progenies do not represent the original genotype (Rivera-Madrid et al. 2006; Pech-Hoil et al. 2017). Even though $B$. orellana can be vegetatively propagated by softwood or hardwood cuttings (Joseph et al. 2011b, 2012; Lombello and Pinto-Maglio 2014), tissue culture and in vitro propagation of selected clones or varieties are the most effective ways to produce genetically uniform plant material (Siril and Joseph 2013) for agricultural and industrial purposes. In vitro biotechnology is thus an important means to massproduce clonal achiote plants with consistent BXN content and growth properties. This present short review explores the

1 Miki-cho, Japan

2 Research Institute of Nyíregyháza, IAREF, University of Debrecen, P.O. Box 12, Nyíregyháza 4400, Hungary

3 Key Laboratory of South China Agricultural Plant Molecular Analysis and Gene Improvement, South China Botanical Garden, The Chinese Academy of Sciences, Guangzhou 510650, China

4 Unity of Plant Biochemistry and Molecular Biology, Centro de Investigación Científica de Yucatán A.C., 97205 Mérida, Yucatán, Mexico 
advances made to date in achiote in vitro tissue culture to better achieve these objectives.

Tissue culture forms the basis of achiote molecular biology and genetic engineering protocols (Teixeira da Silva et al. 2018). The molecular genetics of the biosynthetic pathways underlying BXN production is well understood, but those studies relied almost exclusively on mature seed (Teixeira da Silva et al. 2018), so the use of year-round available clonal tissue-cultured material would greatly benefit achiote genetic and molecular studies. Therefore, the present mini-review provides a summary of the achievements in achiote tissue culture to date that would allow novice researchers unfamiliar with the plant to establish in vitro cultures or that would provide more experienced researchers a basis to optimize and expand their protocols for testing new variables, such as salt or water stress, in a controlled in vitro environment.

\section{The Tissue Culture of Bixa orellana}

The first report in an academic journal on the tissue culture of B. orellana emerged in 1996 (Almeida et al. 1996) using leaf explants, and several protocols were developed thereafter using a range of explant sources (Table 1; Fig. 1). In the following sections, the important procedures required to achieve the tissue culture of achiote are described.

Explant surface disinfection An important part of any tissue culture protocol concerns the successful disinfection of explants, since bacterial or fungal infection would limit all subsequent efforts to establish an in vitro culture, if these contaminants were not suitably removed prior to the introduction of an explant onto sterilized medium. In achiote, leaves or seeds are the most available tissues for explant preparation; however, when older tissues, such as mature stem tissue or mature leaves are used, the risk of medium contamination increases (Table 1). Thus, the most popular explants have been derived from in vitro plants, which in turn were either established from seeds that were surface disinfected and denuded by the removal of the testa (Fig. 1a) or from aseptically excised zygotic embryos. It should be noted here that the zygotic embryo represents genetically different material to the mother genotype, so if genetically identical tissue is required, then somatic tissues must be used. Seedlings, including their hypocotyls (Fig. 1b) and epicotyls, are also popular explant sources, because these tissues are young, actively growing, and almost free of infection if seeds were germinated under aseptic conditions, such as on sterilized vermiculite. The variation in source tissue explains the wide range of protocols listed in Table 1.

As with many tissue culture studies, the vast majority of published protocols did not report the level of infection or the success of the disinfection process, thus it can only be assumed that the described protocol is the most effective. The most commonly employed disinfectants (used in $85.7 \%$ of the protocols in Table 1) are 70\% ( $v / v)$ ethanol (EtOH), 0.5 to $4.5 \%(v / v)$ sodium hypochlorite $(\mathrm{NaOCl})$, and 0.05 to $0.2 \%$ $(w / v)$ mercuric chloride $\left(\mathrm{HgCl}_{2}\right)$, applied alone (in $4.8 \%$ of the cases for $\mathrm{EtOH}$ and $9.5 \%$ for $\mathrm{HgCl}_{2}$ ) or in combination with each other ( $71.4 \%$ of the protocols). Although combining different disinfectants could theoretically eliminate different biological contaminants or improve efficiency, this practice could also negatively impact explant survival and subsequent growth of the explant tissue. The combination of EtOH and $\mathrm{NaOCl}$ was applied in $28.6 \%$ of the studies, whereas $\mathrm{HgCl}_{2}$ was combined either with $\mathrm{EtOH}$ or with $\mathrm{NaOCl}$ in $19 \%$ or $14.3 \%$ of the studies, respectively (Table 1). Only in two studies $(9.5 \%)$ were all three disinfectants combined. Although the choice of disinfectant and the length of the decontamination influence the effectiveness of the disinfection process (Teixeira da Silva et al. 2016), comparative studies of the effectiveness of the application of disinfectants and their combinations have not been conducted in any of the achiote tissue culture studies. Future basic research comparing a range of disinfection protocols for various explant types, ultimately resulting in a single optimized procedure for a wide range of explants, would greatly benefit achiote researchers.

The compounds that have been used for explant decontamination to establish achiote in vitro cultures, as listed in Table 1, are suitable only for the surface disinfection of different explants. However, only recently were a series of endophyte species isolated from different organs of B. orellana, including stems, leaves, twigs, and flowers (Kannan et al. 2017), several of which are frequently used to prepare explants for in vitro culture.

Basal media and plant growth regulators The in vitro environment provides an artificial optimized milieu in which an explant can ultimately be induced to form desired organs or plantlets. While some achiote tissue culture studies tested ideal conditions, several did not, and assumed ideal conditions as were reported in previous studies, including basal medium, photoperiod, growth temperature, and other parameters. In the majority (92\%) of published protocols, Murashige and Skoog (MS) salts and MS vitamins (Murashige and Skoog 1962) were applied to callus, shoot, or somatic embryo induction, and shoot multiplication (Table 1). The rooting medium also primarily consisted of MS salts and vitamins, at full or half strength. In about one-third of the protocols however, $\mathrm{B}_{5}$ vitamins (Gamborg et al. 1968) were used along with MS salts.

When different carbon sources such as sucrose (including cane sugar), fructose, glucose, or mannose were compared in several studies (Paiva Neto et al. 2009; Joseph et al. 2011a; Vijayasekhar et al. 2012), sucrose was reported to be the most effective when applied at 3\% $(w / v)$ for shoot induction and 


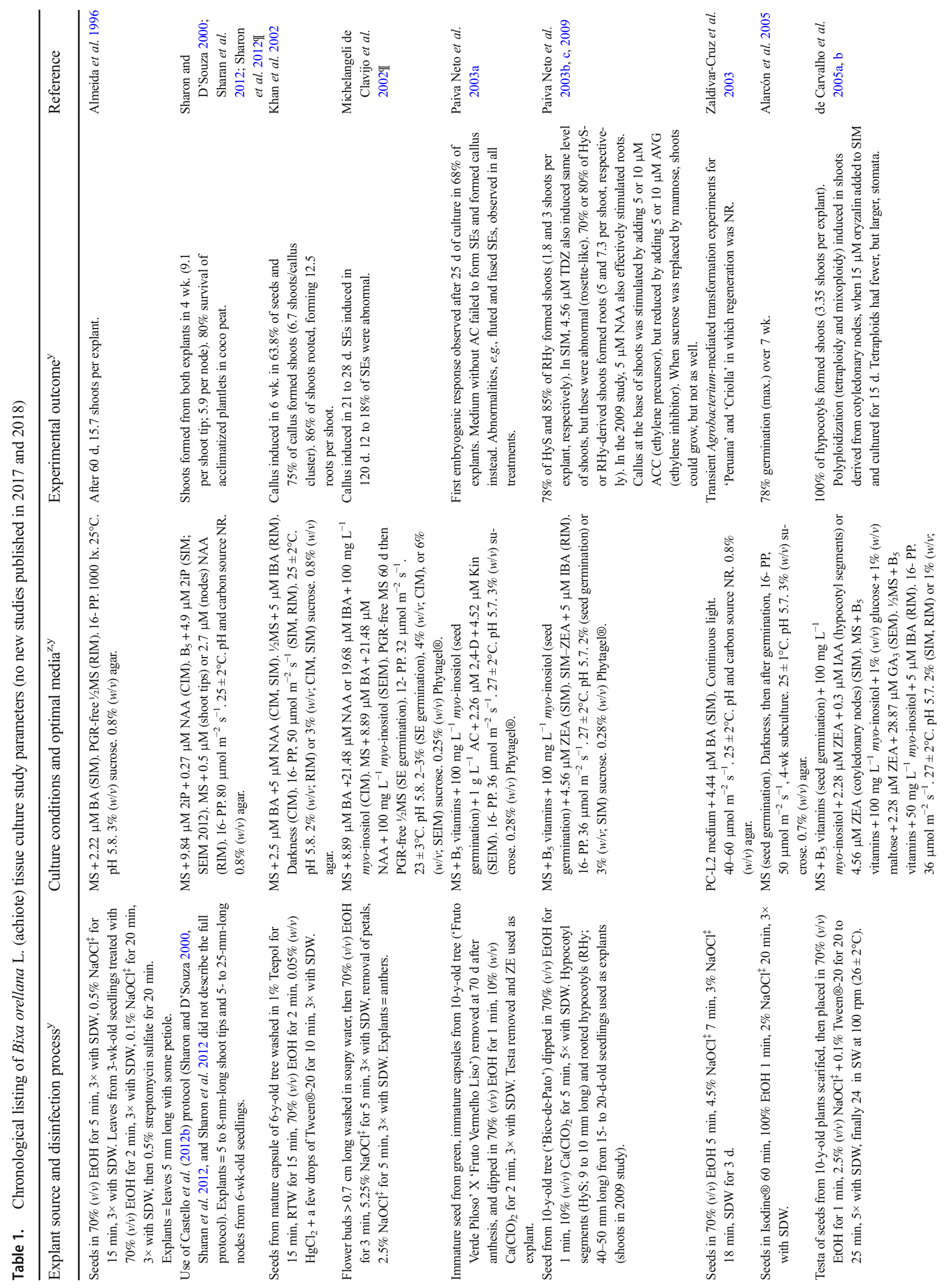




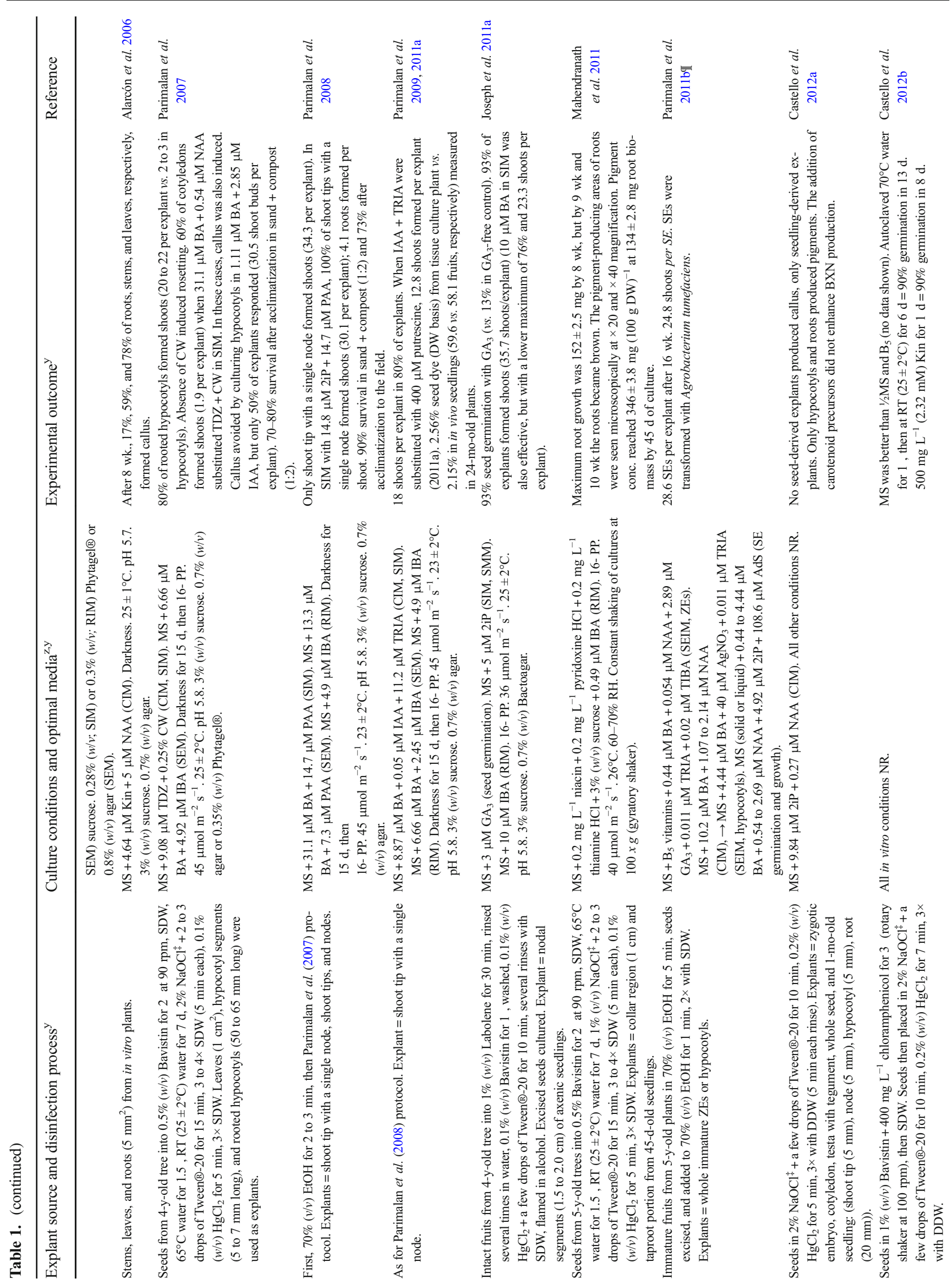




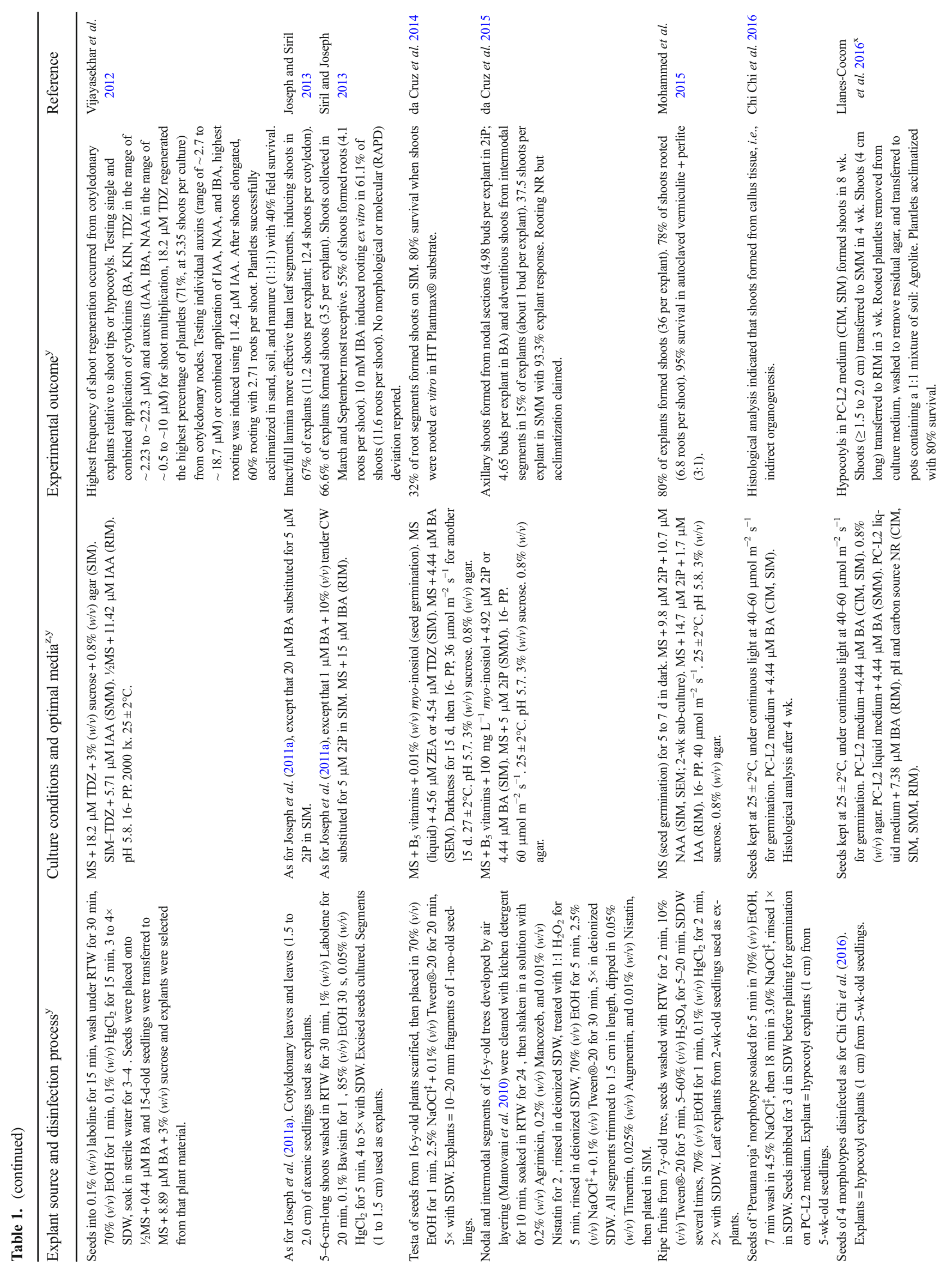


proliferation, but in rooting medium the concentration could be decreased to $2 \%(w / v)$ sucrose (Khan et al. 2002; de Carvalho et al. 2005a, b). It should not be implied that $2 \%$ $(w / v)$ sucrose is ideal for in vitro rooting, merely that this concentration has been used in several cases as effectively as $3 \%(w / v)$ sucrose. It should furthermore not be interpreted by the preceding statement that other carbon sources cannot be used in rooting medium; simply that rooting, as assessed by the percentage of shoots forming roots or by root length or root fresh weight, might not be as high or as productive, as with $3 \%(w / v)$ sucrose.

For shoot induction and development, different cytokinin additions to the medium can be employed, with $N^{6}$ benzyladenine (BA) most often applied alone (35\% of the reports) or in combination with indole-3-acetic acid (IAA; $6 \%$ ) or $\alpha$-naphthaleneacetic acid (NAA; 6\%) (Table 1).

Similarly, a number of cytokinins were successfully applied for somatic embryo induction, but again, most often BA was used, alone or in combination with NAA or indole3 -butyric acid (IBA). The superiority of $N^{6}-\left(\Delta^{2}\right.$-isopentenyl) adenine (2iP) over BA was reported by Joseph et al. (2011a) in shoot regeneration from nodal segments of $B$. orellana seedlings. It was reported that using $5 \mu \mathrm{M} 2 \mathrm{iP} 93 \%$ of explants was responsive, forming 35.7 shoots per explant, whereas BA at $10 \mu \mathrm{M}$ induced a maximum of $76.8 \%$ responsive explants, forming 23.26 shoots per explant. When the effects of BA, thidiazuron (TDZ), and kinetin (Kin) were compared at a concentration range of 0.5 to $5.0 \mathrm{mg} \mathrm{L}^{-1}$ (approximately 2.22 to $22.2 \mu \mathrm{M}), 4.0 \mathrm{mg} \mathrm{L}^{-1}(18.2 \mu \mathrm{M}) \mathrm{TDZ}$ was the most effective for shoot induction (71\% regeneration, 5.35 shoots per culture) from cotyledonary nodes (Vijayasekhar et al. 2012). The same study further reported that regeneration was higher from cotyledonary explants than from shoot tips and hypocotyls. The efficacy of BA and Kin with cotyledonary explants was lower than that of TDZ. $N^{6}$-benzyladenine and Kin were most efficient when applied at $3.0 \mathrm{mg} \mathrm{L}^{-1}(13.35$ and $13.95 \mu \mathrm{M}$, respectively); and their effects were similar to each other (55\% and $65 \%$ shoot regeneration with 2.2 and 2.55 shoots per culture, respectively). Shoot regeneration could not be increased by the combined application of TDZ and different auxins (IAA, IBA, or NAA) in the Vijayasekhar et al. (2012) study, unlike in Parimalan et al. (2008), who reported the synergistic effect of auxin (phenylacetic acid; PAA) and cytokinin (BA) in B. orellana shoot development and proliferation (Table 1). Paiva Neto et al. (2003b) reported that TDZ, when applied at $4.56 \mu \mathrm{M}$, caused rosette-like, abnormal shoot development in shoots developed from hypocotyl or rooted hypocotyl explants.

When shoot development was induced from root explants in liquid medium (da Cruz et al. 2014), TDZ and zeatin (ZEA) induced twofold more shoots (31.7 and 31.9 adventitious buds per root segment, respectively) than BA (15.8 buds per root segment). On semi-solid medium that contained BA, no shoot 

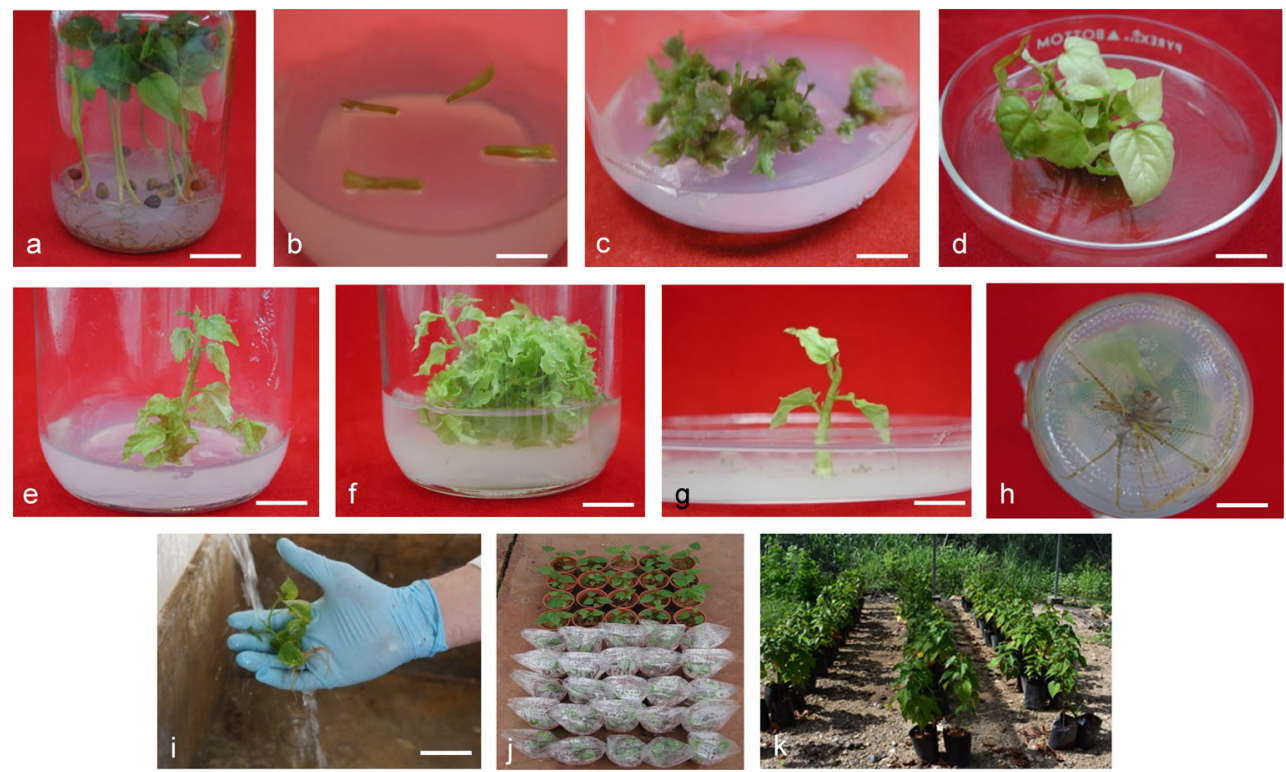

Fig. 1. Depiction of Bixa orellana L. in vitro (achiote) culture and acclimatization. (a) Germination of seeds on PC-L2 medium (Phillips and Collins 1979). Panel a was reproduced from Fig. 2 of Llanes-Cocom et al. (2016); (b) hypocotyl explants on CIM; (c) callus and incipient shoots on SIM. d) Multiple shoots; (e) individual shoot before liquid $S M M$ addition; (f) proliferation of shoots in liquid $S M M$; (g) individual shoot for rooting; roots in RIM. (i) Washing plantlets to remove medium

regeneration was observed, but 4.9 and 2.2 buds per root segment developed on medium containing ZEA and TDZ, respectively (da Cruz et al. 2014). However, the highest proportion $(80 \%)$ of buds developed to normal elongated shoots in liquid medium containing BA, compared with shoot elongation with ZEA- or TDZ-containing media (40\% and 5\%, respectively). Therefore, the efficacy of ZEA and BA was the same, when the final number of elongated shoots (12.76 and 12.64 elongated shoots per root segment, respectively) was considered in the da Cruz et al. (2014) report. Adventitious shoot development was most effective (67\% of explants with 11.2 shoots per leaf and 12.4 shoots per cotyledonary leaf, respectively) when full laminae were used rather than leaf segments (Joseph and Siril 2013).

Godoy Hernández and coworkers (Chi Chi et al. 2016; Llanes-Cocom et al. 2016) established a protocol to regenerate $B$. orellana plants from hypocotyl explants (Fig. $1 b$ ) and generated shoots in $4 \mathrm{wk}$ in the presence of $4.4 \mu \mathrm{M}$ BA (Chi Chi et al. 2016). Indirect organogenesis allowed individual shoots (Fig. 1e) to be rapidly and efficiently proliferated in BA-supplemented liquid medium (Fig. 1f; Llanes-Cocom et al. 2016). A simple, rapid, and inexpensive method to micropropagate $B$. orellana from a single individual using $1 \mu \mathrm{M}$ BA to form shoots (Fig. 1d) from callus (Fig. 1c), and $15 \mu \mathrm{M}$ IBA to induce roots, was developed to ensure the in vitro production of genetically identical plants. The genetic uniformity of in vitro derived plants was also shown by Siril and Joseph (2013). These plants, derived from a single clone residue prior to transfer to pots; (j) plantlets in acclimatization stage; $(\mathbf{k})$ acclimatized plantlets. See Table 1 (Chi Chi et al. 2016; Llanes-Cocom et al. 2016) for details of CIM, SIM, SMM, and RIM. CIM, callus induction medium; RIM, root induction medium; SIM, shoot induction medium; SMM, multiplication induction medium. Bars: (a) $2 \mathrm{~cm}$; (b) $1.3 \mathrm{~cm}$; (c) $1.2 \mathrm{~cm}$; (d) $1.6 \mathrm{~cm}$; (e) $1.5 \mathrm{~cm}$; (f), $1.7 \mathrm{~cm}$; (g) $1.9 \mathrm{~cm}$; (i) $6 \mathrm{~cm}$. Copyright of all images: authors.

and cultured in the field (Fig. $1 k$ ), may achieve stable BXN production and might be considered for replacing current heterogeneous plantations.

The above results suggest that the type of cytokinin that is optimal for shoot development is also likely to be dependent on the type of explant used, although further comparative studies are required to support this assumption.

Inorganic and organic medium additives are able to increase regeneration. In the absence of activated charcoal (AC), Paiva Neto et al. (2003a) did not detect somatic embryo development from zygotic embryos, but when $1 \mathrm{~g} \mathrm{~L}^{-1} \mathrm{AC}$ was added to the medium, $68 \%$ of the explants were responsive. Parimalan et al. (2007) observed shoot development on $80 \%$ of rooted hypocotyls, but in the absence of $0.25 \%(v / v)$ coconut water $(\mathrm{CW})$, abnormal, rosette-like shoots developed. Siril and Joseph (2013), who compared the effect of 5, 10, 15, and $20 \%(v / v)$ of tender coconut water on shoot induction, found that $10 \%(v / v) \mathrm{CW}$ most effectively increased the percentage of responsive nodal segments from 41.7 to $67.0 \%$. By using $10 \%(v / v) \mathrm{CW}$ in shoot induction medium, the number of shoot buds doubled ( $8.9 v$ vs. 4.23), while significant increases in shoot number (3.36 vs. 2.06) and shoot length (3.53 vs. $2.9 \mathrm{~cm}$ ) were also observed (Siril and Joseph 2013).

Rooting of in vitro shoots and plantlet acclimatization Several achiote tissue culture studies have endeavored to induce roots (Fig. 1) from shoots (Fig. 1 $g$ ) formed from shoot tips or axillary buds, or from adventitious shoots induced from 
explants such as leaves. In such cases, as for other plants, an auxin is generally applied. In the case of somatic embryogenesis, an auxin is generally not required for rooting, calling into question whether those studies (Parimalan et al. 2011b; Sharan et al. 2012; Sharon et al. 2012) that employed an auxin to root their supposedly induced somatic embryos were in fact dealing with true somatic embryos. Even though IBA is the most frequently used auxin for inducing roots in achiote (Table 1), when comparing the individual or combined effects of IAA, NAA, and IBA, Vijayasekhar et al. (2012) found that $2.0 \mathrm{mg} \mathrm{L}^{-1}(11.42 \mu \mathrm{M})$ IAA was the most effective $(60 \%$ rooting and 2.71 roots per shoot after $35 \mathrm{~d}$ on root induction medium), whereas IBA was least effective even at its optimal concentration of $2.5 \mathrm{mg} \mathrm{L}^{-1}(12.25 \mu \mathrm{M})$, with $25 \%$ rooting and 1.38 roots per shoot after $62 \mathrm{~d}$.

In vitro-rooted achiote shoots (Fig. 1) can be successfully acclimatized in coco peat alone, 1:2 mixture of sand and compost, 3:1 mixture of vermiculite and perlite, or 1:1:1 mixture of sand, soil, and manure (Table 1; Fig. 1i,j). Plant survival after acclimatization (Fig. $1 \mathrm{k}$ ) varied between 70 and $90 \%$, although Vijayasekhar et al. (2012) reported that field survival was only 40\%. Ex vitro rooting in HT Plantmax ${ }^{\circledR}$ (Eucatex, Salto, Brazil) substrate and acclimatization of elongated in vitro shoots in a single step (da Cruz et al. 2014) shortened the period necessary for obtaining plants from shoot culture (rooted and acclimatized plants within $40 \mathrm{~d}$ ) and ensured a high (80\%) survival rate.

\section{Secondary metabolite production in tissue culture Although} seeds are the in vivo carotenoid-storage organs of achiote, BXN and other carotenoids have been detected in different organs or tissues in vitro (Mahendranat et al. 2011; Castello et al. 2012a; Zhai et al. 2014). This indicates possible industrial secondary metabolite production by using in vitro plant tissues. The ability to produce $\mathrm{BXN}$ in in vitro cultures would allow for year-round production, independent of the ability to produce and harvest seeds from field-grown plants in a seasonal manner. Moreover, it could ensure the selection of clones with high BXN production capacity. Only limited studies exist on secondary metabolite, including BXN, production in vitro, and further investigations are needed to optimize conditions for BXN production.

A study by Castello et al. (2012a) found differences in secondary metabolite production, depending on the genetic background, explant source, and age of callus. For instance, callus derived from hypocotyl explants produced less BXN than callus derived from root explants; young callus produced $\mathrm{BXN}$, but production decreased as callus aged; and BXN production from either hypocotyl- or root-derived callus could not be increased, even when a precursor (mevalonic acid) or intermediate compound (gerany-geranyl-pyrophosphate) of carotenoid biosynthesis was added to medium.
Mahendranath et al. (2011) induced pigment production (maximum of $346 \pm 3.8 \mathrm{mg}$ per $100 \mathrm{~g}$ dry weight (DW) of roots) in in vitro root culture on MS medium with $0.1 \mathrm{mg} \mathrm{L}^{-1}(0.49 \mu \mathrm{M})$ IBA after $45 \mathrm{~d}$ of culture. Fungal bioelicitors have also been employed to increase $\mathrm{BXN}$ production (Giridhar and Parimalan 2010). When Zhai et al. (2014) added a signaling molecule, methyl-jasmonate, to modified liquid MS medium containing $7.7 \mathrm{mM} \mathrm{NH}_{4}{ }^{+}$and $22.85 \mathrm{mM} \mathrm{NO}_{3}{ }^{-}$ for 24 , a 15-d-old hairy root culture of $B$. orellana (line 15) transformed with the Bixa orellana carotenoid cleavage dioxygenase $4 a$ (BoCCD4a) gene (Sankari et al. 2016) successfully increased the production of secondary metabolites, including ishwarane, ellagic acid, 5-tocotrienol, BXN, stigmasterol, $\beta$-sitosterol, ursolic acid, maslinic acid, inositol, and arjunolic acid; however, the production of each was not quantified.

\section{Conclusions, Limitations, and Future Perspectives}

There are approximately three dozen tissue culture studies on achiote, all of which were conducted within the past two decades. Compared with many other commercially, medicinally, and pharmaceutically important species, this is not a large number of studies. Some of the protocols shown in Table 1 offer what may appear to be contradictory findings or different optimized conditions, but these differences likely reflect (1) different plant material from different environments, genotypes, explants, or culture conditions, or disparate levels of rigor of the research; and (2) a lack of studies that measured the effectiveness of protocols or their reproducibility, either because material was scarce or because funding for largescale studies to assess optimized conditions that are independent of germplasm source or protocol were also scarce. Largescale comparative studies have not yet been conducted on basic disinfection protocols or on ideal parameters reported in the studies highlighted in Table 1 but should be carried out and applied to a wide range of explants and genotypes.

Besides in vitro propagation (organogenesis and somatic embryogenesis) of selected germplasm, there are possibilities for using other tissue culture methods in achiote breeding. From a breeding point of view, it is essential to have a germplasm repository of this species that focuses on pigment diversity and to implement an in vitro androgenesis protocol to create double haploids and thus attain pure lines (RiveraMadrid et al. 2016). Alternatively, the ability to induce flowers in vitro, as has been successfully done with orchids (Teixeira da Silva et al. 2014), would permit the controlled production of flowers and seeds in vitro and would thus allow for seed production under controlled environmental 
conditions. However, although such a method would be useful for the production of flowers from which pollen could be harvested independent of season, given the cross-pollination nature of achiote, seed would likely be of variable yield and quality. Thus, such a method would not be appropriate for use in traditional breeding programs and further, its effect on BXN production would still need to be tested. Scientists involved in achiote research might consider exploring the use of ultrasound or sonication (Teixeira da Silva and Dobránszki 2014), thin cell layers (Teixeira da Silva and Dobránszki 2013), or magnetic fields (Teixeira da Silva and Dobránszki 2015) to study growth and development, thus supplementing comprehensive analyses of embryo structure and development conducted by Chopra and Kaur (1965) or of the androecium by Decraene (1989), maximizing organogenesis, or increasing the production of secondary metabolites.

Large-scale experiments that test the ability to induce important secondary metabolites, primarily $\mathrm{BXN}$, from a range of explants, media, and genotypes are needed. The use of bioreactors or feeding precursors into such systems or the use of Agrobacterium rhizogenes-induced hairy roots would allow for the automated production of biomass and ultimately of BXN and NBX, similar to other mass production systems used for food colorants (de Boer 2014). Although molecular markers have been used in marker-assisted breeding in achiote or to assess genetic diversity of fruit (Teixeira da Silva et al. 2018), they have not been used to assess the genetic stability of tissue culture regenerants, but should be, in order to ensure clonal stability.

Clearly, much work remains to be done on the optimization of achiote tissue culture, whether for mass propagation, breeding, or in vitro bixin production, and it is hoped that the current review provides an expedient starting point for such investigations.

Acknowledgements Open access funding provided by University of Debrecen (DE).

Funding information The research conducted by J. A. Teixeira da Silva and J. Dobránszki was financed by the Higher Education Institutional Excellence Programme of the Ministry of Human Capacities in Hungary, within the framework of the Biotechnology thematic programme of the University of Debrecen (20428-3/2018/FEKUTSTRAT). The study and submission for publication were approved by the University of Debrecen (BPTR/DEENK/0003/2019). R. Rivera-Madrid was supported by the Consejo Nacional de Ciencia y Tecnología (CONACYT) with grant No. 220259. G. Godoy was financially supported by CONACYT for Project No. 248736.

\section{Compliance with ethical standards}

Conflict of interest The authors declare that they have no conflicts of interest.
Open Access This article is distributed under the terms of the Creative Commons Attribution 4.0 International License (http:// creativecommons.org/licenses/by/4.0/), which permits unrestricted use, distribution, and reproduction in any medium, provided you give appropriate credit to the original author(s) and the source, provide a link to the Creative Commons license, and indicate if changes were made.

\section{References}

Alarcón PJC, Castaño PHI, Corrales GLL, Jiménez RSL, Díaz CA (2006) Evaluation of some growth regulators combination for callus induction in annatto (Bixa orellana L.) active plant against snake bites. Vitae 13:17-23 (in Spanish with English abstract)

Alarcón PJC, Quinchia BLA, Ciro GGL, Jiménez RSL, Díaz CA (2005) Intracapsular seed collection, an important variable in in vitro annatto (Bixa orellana L.) germination, plant to treat snakebites. Vitae 12: 29-35 (in Spanish with English abstract)

Almeida JL, Almeida FCG, Nunes RDEP, Almeida FAG (1996) Bud initiation in leaf explants of annatto seedlings in different cytokinins. Ciênc Rural 26:45-49 (in Portuguese with English abstract)

Baer DF (1976) Systematics of the genus Bixa and geography of the cultivated annatto. $\mathrm{PhD}$ thesis, University of California, LA, USA, 240 pp. https://eurekamag.com/research/000/762/000762617.php. Accessed 28 Feb 2019

Castello MC, Sharan M, Sharon M (2012a) In vitro culture studies of Bixa orellana L: II - Bixin accumulation in root and hypocotyl derived callus. Eur J Exp Biol 2:151-155

Castello MC, Sharan M, Sharon M (2012b) In vitro culture studies of Bixa orellana L: IV - in vitro and in vivo trials for breaking the dormancy of seeds of Bixa orellana. Eur J Exp Biol 2:174-179

Chi Chi LC, Barredo Pool FA, Godoy Hernández G, Rivera-Madrid R, Pinzón López L, Villanueva Cohuoh E (2016) Análisis histológico del proceso morfogénico de Bixa orellana. Rev Centro Graduados e Investigación (Instituto Tecnológico de Mérida) 31:62-64 (in Spanish with English abstract)

Chopra RN, Kaur H (1965) Embryology of Bixa orellana Linn. Phytomorphology 15:211-214

da Cruz ACF, Pinheiro MVM, Xavier A, Otoni WC, Costa MGC, Paiva Neto VB, Rêgo MM (2015) In vitro regeneration of annatto (Bixa orellana L.) plantlets from nodal and internodal adult stem segments. Acta Hortic 1083:335-346

da Cruz ACF, Rocha DI, Iarema L, Ventrella MC, Costa MGC, Neto VBP, Otoni WC (2014) In vitro organogenesis from root culture segments of Bixa orellana L. (Bixaceae). In Vitro Cell Dev Biol Plant 50:76-83

de Boer L (2014) Biotechnological production of colorants. In: Zorn H, Czermak P (eds) Biotechnology of Food and Feed Additives (Volume 143 of the series Advances in Biochemical Engineering/ Biotechnology). Springer, Berlin, pp 51-89

de Carvalho JFRP, de Carvalho CRP, Otoni WC (2005a) In vitro regeneration of annatto (Bixa orellana L.) from various explants. Revista Árvore 29:887-895 (in Portuguese with English abstract)

de Carvalho JFRP, de Carvalho CRP, Otoni WC (2005b) In vitro induction of polyploidy in annatto (Bixa orellana). Plant Cell Tissue Organ Cult 80:69-75

Decraene RLP (1989) Floral development of Cochlosperum tinctorium and Bixa orellana with special emphasis on the androecium. Am J Bot 76:1344-1359

Gamborg OL, Miller RA, Ojima K (1968) Nutrient requirements of suspension cultures of soybean root cells. Exp Cell Res 50:151-158 
Giridhar P, Parimalan R (2010) A biotechnological perspective towards improvement of annatto color production for value addition - the influence of biotic elicitors. Asia-Pacific J Mol Biol Biotechnol 18: 77-79

Joseph N, Siril EA (2013) Multiplication of annatto (Bixa orellana L.) using cotyledons and leaf explants. Res Plant Biol 3:24-32

Joseph N, Siril EA, Nair GM (2011a) An efficient in vitro propagation methodology for annatto (Bixa orellana L.). Physiol Mol Biol Plants 17:263-270

Joseph N, Siril EA, Nair GM (2011b) A comparison of conventional cloning options for annatto (Bixa orellana L.). J Hortic Sci Biotechnol 86:446-451

Joseph N, Siril EA, Nair GM (2012) Reproductive characterization and preliminary studies on controlled breeding of annatto (Bixa orellana L.). Plant Sys Evol 298:239-250

Kannan KP, Ashwanandhini G, Hemasindhu B, Vinothkumar S, MadhanKumar D, Senthamarai M (2017) Investigation of endophytic fungi associated with Bixa orellana 1., a medicinal plant collected from Western Ghats of Sathyamangalam - a first report. J Bacteriol Mycol 5:381-385

Khan PSSV, Prakash E, Rao KR (2002) Callus induction and plantlet regeneration in Bixa orellana L., an annatto-yielding tree. In Vitro Cell Dev Biol Plant 38:186-190

Leal F, Michelangeli De Clavijo CM (2010) Annatto: a natural dye from the tropics. Chron Hortic 50:34-36

Llanes-Cocom JR, Raul Ávila-Cervantes R, Cano-Tun M, ValladaresGarcía P, Pérez González A, Carrillo-Pech M, Avilés-Berzunza E, Rivera-Madrid R, Pinzón-López L, Villanueva-Couoh E, GodoyHernández G (2016) Micropropagación de clonas regeneradas a partir de los explantes de hipocótilo de cuatro morfotipos de Bixa orellana. Rev Centro Graduados e Investigación (Instituto Tecnológico de Mérida) 31:68-71 (in Spanish with English abstract)

Lombello RA, Pinto-Maglio CAF (2014) Cytogenetics and reproductive biology of Bixa orellana L. (Bixaceae). Cytologia 79:379-386

Mahendranath G, Venugopalan A, Parimalan R, Giridhar P, Ravishankar GA (2011) Annatto pigment production in root cultures of achiote (Bixa orellana L.). Plant Cell Tissue Organ Cult 106:517-522

Mantovani NC, Grando MF, Xavier A, Otoni WC (2010) Vegetative rescue of adult genotypes of annatto (Bixa orellana L.) by air layering. Ciênc Florestal 20:403-410 (in Portuguese)

Michelangeli de Clavijo CC, Artioli PIG, Medina AMM (2002) Somatic embryogenesis in annatto. Agron Trop 52:523-541 (in Spanish with English abstract)

Mohammed A, Chiruvella KK, Namsa ND, Ghanta RG (2015) An efficient in vitro shoot regeneration from leaf petiolar explants and $e x$ vitro rooting of Bixa orellana L. - a dye yielding plant. Physiol Mol Biol Plants 21:417-424

Murashige T, Skoog F (1962) A revised medium for rapid growth and bioassays with tobacco tissue culture. Physiol Plant 15:473-497

Paiva Neto VB, Carvalho CR, Otoni WC (2003c) Mannose: a potential selection system for genetic transformation of annatto. Biol Plant 47: $441-444$

Paiva Neto VB, de Botelho MN, Aguiar R, Silva EAM, Otoni WC (2003a) Somatic embryogenesis from immature zygotic embryos of annatto (Bixa orellana L.). In Vitro Cell Dev Biol Plant 39: $629-634$

Paiva Neto VB, Mota TR, Otoni WC (2003b) Direct organogenesis from hypocotyl-derived explants of annatto (Bixa orellana). Plant Cell Tissue Organ Cult 75:159-167

Paiva Neto VB, Reis LB, Finger FL, Barros RS, Carvalho CR, Otoni WC (2009) Involvement of ethylene in the rooting of seedling shoot cultures of Bixa orellana L. In Vitro Cell Dev Biol Plant 45:693-700

Parimalan R, Giridhar P, Gururaj HB, Ravishankar GA (2007) Organogenesis from cotyledon and hypocotyls derived explants of japhara (Bixa orellana L.). Act Bot Croat 66:153-160
Parimalan R, Giridhar P, Gururaj HB, Ravishankar GA (2008) Mass multiplication of Bixa orellana L. through tissue culture for commercial propagation. Ind Crop Prod 28:122-127

Parimalan R, Giridhar P, Gururaj HB, Ravishankar GA (2009) Micropropagation of Bixa orellana using phytohormones and triacontanol. Biol Plant 53:347-350

Parimalan R, Giridhar P, Ravishankar GA (2011a) Enhanced shoot organogenesis in Bixa orellana L. in the presence of putrescine and silver nitrate. Plant Cell Tissue Organ Cult 105:285-290

Parimalan R, Venugopal A, Giridhar P, Ravishankar GA (2011b) Somatic embryogenesis and Agrobacterium-mediated transformation in Bixa orellana L. Plant Cell Tissue Organ Cult 105:317-328

Pech-Hoil R, Ferrer MM, Aguilar-Espinosa M, Valdez-Ojeda R, GarzaCaligaris LE, Rivera-Madrid R (2017) Variation in the mating system of Bixa orellana L. (achiote) under three different agronomic systems. Sci Hortic 223:31-37

Phillips GC, Collins GB (1979) In vitro tissue culture of selected legumes and plant regeneration from callus cultures of red clover. Crop Sci 19:59-64

Rivera-Madrid R, Aguilar-Espinosa M, Cárdenas-Conejo Y, GarzaCaligaris LE (2016) Carotenoid derivates in achiote (Bixa orellana) seeds: synthesis and health promoting properties. Front Plant Sci 7: 1406. https://doi.org/10.3389/fpls.2016.01406

Rivera-Madrid R, Escobedo-GM RM, Balam-Galera E, Vera-Ku M, Harries H (2006) Preliminary studies toward genetic improvement of annatto (Bixa orellana L.). Sci Hortic 109:165-172

Saha PD, Sinha K (2012) Natural dye from bixa seeds as a potential alternative to synthetic dyes for use in textile industry. Desal Water Treat 40:298-301

Sankari M, Hemachandran H, Anantharaman A, Babu S, Rivera-Madrid R, Doss GPC, Fulzele DP, Siva R (2016) Identifying a carotenoid cleavage dioxygenase $4 \mathrm{a}$ gene and its efficient Agrobacterium-mediated genetic transformation in Bixa orellana L. Appl Biochem Biotechnol 179:697-714

Sharan M, Sharon M, Castello MC (2012) In vitro culture studies of Bixa orellana L: III Plant regeneration from roots through direct and indirect somatic embryogenesis. Eur J Exp Biol 2:156-162

Sharon M, D'Souza MC (2000) In vitro clonal propagation of annatto (Bixa orellana L.). Curr Sci 78:1532-1535

Sharon M, Sharan M, Castello MC (2012) In vitro culture studies of Bixa orellana L: I - differential requirements for plant regeneration from hypocotyl, leaf, cotyledonary leaf and root explants. Eur J Exp Biol 2:142-150

Siril EA, Joseph N (2013) Micropropagation of annatto (Bixa orellana L.) from mature tree and assessment of genetic fidelity of micropropagated plants with RAPD markers. Physiol Mol Biol Plants 19:147-155

Teixeira da Silva JA (2012) Is BA (6-benzyladenine) BAP (6benzylaminopurine)? Asian Austral J Plant Sci Biotechnol 6(Special Issue 1):121-124

Teixeira da Silva JA, Dobránszki J (2013) Plant thin cell layers: a 40-year celebration. J Plant Growth Reg 32:922-943

Teixeira da Silva JA, Dobránszki J (2014) Sonication and ultrasound: impact on plant growth and development. Plant Cell Tissue Organ Cult 117:131-143

Teixeira da Silva JA, Dobránszki J (2015) How do magnetic fields affect plants in vitro? In Vitro Cell Dev Biol Plant 51:233-240

Teixeira da Silva JA, Dobránszki J, Rivera-Madrid R (2018) The biotechnology (genetic transformation and molecular biology) of Bixa orellana L. (achiote). Planta 248:267-277

Teixeira da Silva JA, Kerbauy GB, Zeng S-J, Chen Z-L, Duan J (2014) In vitro flowering of orchids. Crit Rev Biotechnol 34:56-76

Teixeira da Silva JA, Kulus D, Zhang X, Zeng S-J, Ma G-H, Piqueras A (2016) Disinfection of explants for saffron (Crocus sativus L.) tissue culture. Environ Exp Biol 14:183-198 
The Plant List (2019) Bixa. http://www.theplantlist.org/tpl1.1/search?q= Bixa. Accessed 25 Feb 2019

Tupuna DS, Paese K, Stanisçuaski Guterres S, Jablonski A, Hickmann Flôres S, Oliveira Rios A (2018) Encapsulation efficiency and thermal stability of norbixin microencapsulated by spray-drying using different combinations of wall materials. Ind Crop Prod 111:846855

Vijayasekhar VE, Satya AK, Sudhakar P, Sambasivarao KRS (2012) Improved in vitro shoot multiplication of Bixa orellana under the influence of phytohormones particularly thidiazuron. J Pharm Res 5: 1144-1147
Zaldívar-Cruz JM, Ballina-Gómez H, Guerrero-Rodríguez C, AvilésBerzunza E, Godoy-Hernández GC (2003) Agrobacterium-mediated transient transformation of annatto (Bixa orellana) hypocotyls with the GUS reporter gene. Plant Cell Tissue Organ Cult 73:281284

Zhai B, Clark J, Ling T, Connelly M, Medina-Bolivar F, Rivas F (2014) Antimalarial evaluation of the chemical constituents of hairy root culture of Bixa orellana L. Molecules 19:756-766 